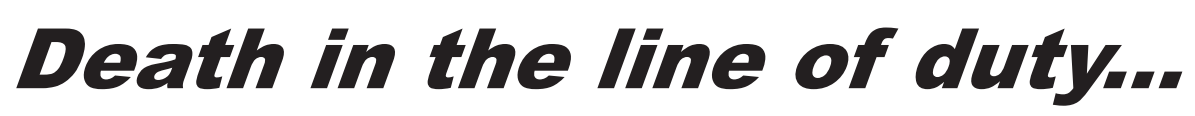

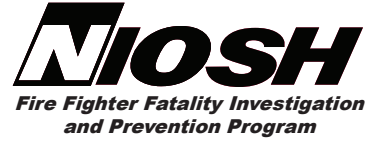

A summary of a NIOSH fire fighter fatality investigation

July, 2014

\section{Fire Fighter Suffers Sudden Cardiac Death at Structure Fire - West Virginia}

\section{Executive Summary}

On June 24, 2013, a 62-year-old male volunteer fire fighter ("FF") responded on a mutual aid call to a mobile home fire at 1418 hours. Responding in the fire department's engine, the FF arrived on scene at approximately 1500 hours. After trying to remove large debris near the trailer, he became lightheaded and rested in the shade. Paramedics assigned to rehabilitation responded and helped the FF walk to the rehab area. As the FF arrived at rehab he lost consciousness and went into cardiac arrest. Cardiopulmonary resuscitation (CPR) and advanced life support (ALS), including cardiac monitoring, multiple defibrillation attempts, ventilation, and intravenous line placement, began immediately. Despite CPR and ALS for over an hour on the scene, in transport, and at the hospital, the FF died. The death certificate, completed by the state first deputy chief medical examiner listed "sudden death due to ischemic heart disease" as the cause of death. The autopsy report, also completed by the state first deputy chief medical examiner, listed "likely fatal irregularity of the heartbeat occurring in the setting of severe coronary artery disease of the heart with contributory pathologic enlargement of the heart muscle due to long-standing high blood pressure" as the cause of death. Given the FF's underlying cardiovascular disease, NIOSH investigators concluded that responding to the structure fire and the physical exertion of trying to pull heavy debris away from the structure could have triggered a fatal cardiac arrhythmia.
The first three recommendations may have prevented the FF's death. The remaining recommendations address general safety and health issues.

Provide preplacement and annual medical evaluations to all fire fighters in accordance with NFPA 1582, Standard on Comprehensive Occupational Medical Program for Fire Departments, to identify fire fighters at increased risk for coronary heart disease (CHD).

Ensure exercise stress tests are performed on fire fighters at increased risk for CHD.

Ensure that fire fighters are cleared for duty by a physician knowledgeable about the physical demands of fire fighting, the personal protective equipment used by fire fighters, and the various components of NFPA 1582.

Phase in a mandatory comprehensive wellness and fitness program for fire fighters.

Perform a candidate and an annual physical performance (physical ability) evaluation for all members.

Provide fire fighters with medical clearance to wear a self-contained breathing apparatus (SCBA) as part of the fire department's medical evaluation program.

Conduct annual respirator fit testing. 


\section{Fire Fighter Suffers Sudden Cardiac Death at Structure Fire - West Virginia}

The National Institute for Occupational Safety and Health (NIOSH), an institute within the Centers for Disease Control and Prevention (CDC), is the federal agency responsible for conducting research and making recommendations for the prevention of work-related injury and illness. In 1998, Congress appropriated funds to NIOSH to conduct a fire fighter initiative that resulted in the NIOSH "Fire Fighter Fatality Investigation and Prevention Program" which examines line-of-duty-deaths or on duty deaths of fire fighters to assist fire departments, fire fighters, the fire service and others to prevent similar fire fighter deaths in the future. The agency does not enforce compliance with State or Federal occupational safety and health standards and does not determine fault or assign blame. Participation of fire departments and individuals in NIOSH investigations is voluntary. Under its program, NIOSH investigators interview persons with knowledge of the incident who agree to be interviewed and review available records to develop a description of the conditions and circumstances leading to the death(s). Interviewees are not asked to sign sworn statements and interviews are not recorded. The agency's reports do not name the victim, the fire department or those interviewed. The NIOSH report's summary of the conditions and circumstances surrounding the fatality is intended to provide context to the agency's recommendations and is not intended to be definitive for purposes of determining any claim or benefit. For further information, visit the program website at www.cdc.gov/niosh/fire or call toll free 1-800-CDC-INFO (1-800-232-4636). 


\section{Fire Fighter Suffers Sudden Cardiac Death at Structure Fire - West Virginia}

\section{Introduction \& Methods}

On June 24, 2013, a 62-year-old male volunteer FF suffered cardiac arrest at a structure fire. NIOSH contacted the affected fire department on July 9, 2013, to gather information and on January 16,2014 , to initiate the investigation. On January 27, 2014, a safety and occupational health specialist from the NIOSH Fire Fighter Fatality Investigation and Prevention Program investigated the incident.

During the investigation, NIOSH personnel interviewed the following people:

- Fire chief

- FF's spouse

NIOSH personnel reviewed the following documents:

- Fire department standard operating procedures

- Fire department annual report for 2013

- Fire department incident reports

- Emergency medical service (ambulance) report

- Hospital emergency department (ED) report

- Death certificate

- Autopsy report

- Primary care physician records

\section{Investigative Results}

Incident. On June 24, 2013, at 1418 hours, the fire department was dispatched to provide extra water at a mobile home fire. The FF drove Engine 32 to the fire scene, which took about 45 minutes. Weather conditions included a temperature of 87 degrees Fahrenheit $\left({ }^{\circ} \mathrm{F}\right)$ and relative humidity of $46 \%$, giving a heat index of $88^{\circ} \mathrm{F}$ [NOAA 2013].

Engine 32 arrived on the scene at approximately 1500 hours. The FF, wearing full turnout gear but no self-contained breathing apparatus, walked up the 50-yard driveway to assist with exterior operations. His first task was to remove a large, heavy piece of sheet metal from the fire area. After an unsuccessful attempt to remove the object, the FF reported feeling like he was going to pass out. A Captain assisted the FF to a shaded area and took the FF's coat, helmet, hood, and gloves off (approximately 1510 hours). The Captain used water from a fire hose to cool the FF before summoning the on-scene paramedics (1515 hours).

The paramedics walked with the FF to the rehab area (about 30 yards away) for a medical evaluation. In rehab, his pulse was measured at 124 beats per minute (normal 60-120). Then, as the paramedic turned to notify a nearby fire fighter that the FF would not be returning to fire suppression duties, the FF lost consciousness (1520 hours), then went into cardiac arrest (1521 hours).

The paramedics began CPR and ALS. This included cardiac monitoring, Combitube $\mathbb{R}$ placement with oxygen, intravenous line placement, and cardiac resuscitation medications. Two shocks (defibrillations) were delivered, but his heart rhythm converted to a junctional rhythm, and CPR continued. At 1532 hours, the ambulance departed the fire scene for the local hospital's ED.

The ambulance arrived at the hospital's ED at 1546 hours. In the ED the Combitube $\AA$ was removed, and the FF was intubated. Additional cardiac resuscitation medications were administered resulting in the FF's heart rhythm changing to ventricular tachycardia. He was shocked again, but this time his heart 


\section{Fire Fighter Suffers Sudden Cardiac Death at Structure Fire - West Virginia}

\section{Investigative Results (cont.)}

rhythm reverted to pulseless electrical activity. At 1640 hours, after 1 hour and 20 minutes of CPR and ALS in the field and the ED, the FF was pronounced dead by the attending physician; resuscitation efforts were discontinued.

Medical Findings. The death certificate, completed by the state first deputy chief medical examiner listed "sudden death due to ischemic heart disease" as the cause of death. The autopsy report, also completed by the state first deputy chief medical examiner, listed "likely fatal irregularity of the heartbeat occurring in the setting of severe coronary artery disease of the heart with contributory pathologic enlargement of the heart muscle due to long-standing high blood pressure" as the cause of death. Pertinent findings from the autopsy are listed in Appendix A.

The FF's risk factors for CHD included: age > 45 , male gender, former smoker, positive family history of CHD, hypertension, hyperlipidemia, and obesity. In 1992, the FF suffered a myocardial infarction (heart attack). In 2000, he experienced angina; a positive cardiac catheterization led to successful coronary artery bypass graft surgery (three-vessel bypass). As of December 2012, the FF was being followed by his primary care physician for stable angina, hypertension, and hyperlipidemia. His most recent blood pressure was 125/80 millimeters of mercury (December 2012); his lipid values in October 2012 included cholesterol of 251 milligrams per deciliter (mg/ dL) (normal is 100-199), triglycerides of 614 $\mathrm{mg} / \mathrm{dL}$ (normal is 0-149), and a high density lipoprotein (HDL) of $31 \mathrm{mg} / \mathrm{dL}$ (normal is $>39$ ). His low density lipoprotein (LDL) could not be calculated because his triglyceride level was above $400 \mathrm{mg} / \mathrm{dL}$ (normal LDL level is 0-99). The FF's stable angina (mild chest tightness on exertion and dyspnea on exertion) recurred in December 2012. His physician recommended continued use of sublingual nitroglycerin for angina and a weight loss program with supervised exercise.

The FF was 69 inches tall and weighed 205 pounds at his last primary care physician visit in 2012, giving him a body mass index of 30.4 kilograms per meter squared. A body mass index $>30.0$ kilograms per meter squared is considered obese [CDC 2011]. The FF walked daily and performed other fitness activities at a local gym.

\section{Description of the Fire Department}

At the time of the NIOSH investigation, the fire department consisted of one fire station with 20 volunteer uniformed personnel serving 25,000 residents in a geographic area of 15 square miles. In 2013, the fire department responded to 247 calls.

Employment and Training. The fire department requires new fire fighter applicants to be 18 years of age, have a valid state driver's license, have a high school diploma or a general equivalency diploma, and pass an interview with the fire chief prior to a vote by the fire department membership. The successful applicant is then placed in an 8-weekend fire fighter I training program to become trained to the fire fighter I level. The FF was certified as a fire fighter I and II, driver/ operator, and in hazardous materials awareness. He had 8 years of fire fighting experience.

Preplacement and Annual Medical Evaluations. Preplacement and/or annual medical evaluations are not required by the fire department. Members 


\section{Fire Fighter Suffers Sudden Cardiac Death at Structure Fire - West Virginia}

\section{Description of the FD (cont.)}

injured on duty must be evaluated by their primary care physician. Once this evaluation is completed, the physician makes a determination regarding medical clearance for fire fighting duties and forwards this decision to the fire chief. No medical clearance to wear a respirator nor annual self-contained breathing apparatus facepiece fit test is required.

\section{Physical Agility Tests and Wellness/Fitness}

Programs. Physical agility tests are not required for candidates or members. The fire department does not have a wellness/fitness program. Exercise equipment is not available in the fire station. The FF exercised at a local gym by walking 30 minutes and lifting weights almost every day.

\section{Discussion}

Atherosclerotic Coronary Heart Disease. In the United States, atherosclerotic CHD is the most common risk factor for cardiac arrest and sudden cardiac death [Meyerburg and Castellanos 2008]. Risk factors for its development include age older than 45 , male gender, family history of CHD, smoking, high blood pressure, high blood cholesterol, diabetes, and obesity/physical inactivity [Greenland et al. 2010; NHLBI 2012; AHA 2014]. The FF had known CHD plus three modifiable CHD risk factors (treated high blood pressure, high blood cholesterol, and obesity).

The narrowing of the coronary arteries by atherosclerotic plaques occurs over many years, typically decades [Libby 2013]. However, the growth of these plaques probably occurs in a nonlinear, often abrupt fashion. Heart attacks typically occur with the sudden development of complete blockage (occlusion) in one or more coronary arteries that have not developed a collateral blood supply. This sudden blockage is primarily due to blood clots (thromboses) forming on top of atherosclerotic plaques [Libby 2013].

Establishing a recent (acute) heart attack requires any of the following: characteristic electrocardiography (EKG) changes, elevated cardiac enzymes, or coronary artery thrombus. In this case, the FF did not have a heart rhythm to conduct an EKG, cardiac enzymes were not tested, and no coronary artery thrombus was identified at autopsy. Given that heart attacks can occur without a coronary thrombus, it is possible that the FF had a heart attack [Davies 1992; Farb et al. 1995]. Because he did not report angina at the fire scene and no thrombus was found at autopsy, the more likely etiology of his sudden cardiac death was cardiac arrhythmia.

Primary Arrhythmia. Primary cardiac arrhythmia (e.g., ventricular tachycardia/ fibrillation) was probably responsible for the FF's sudden cardiac death. Risk factors for arrhythmias include cardiac disease, heart attack, sleep apnea, dietary supplements, smoking, alcohol, drug abuse, medications, diabetes, and hyperthyroidism [AHA 2012; Mayo Clinic 2013]. The FF's autopsy revealed his severe atherosclerotic CHD, cardiomegaly, and left ventricular hypertrophy (discussed below). These cardiac conditions increase the risk for primary arrhythmia [AHA 2012].

Cardiomegaly/Left Ventricular Hypertrophy. On autopsy, the FF was found to have left ventricular hypertrophy and an enlarged heart (cardiomegaly). These conditions increase the risk for sudden cardiac death [Levy et al. 1990]. 


\section{Fire Fighter Suffers Sudden Cardiac Death at Structure Fire - West Virginia}

\section{Discussion (cont.)}

Hypertrophy of the heart's left ventricle is a relatively common finding among individuals with long-standing hypertension, a heart valve problem, or chronic cardiac ischemia (reduced blood supply to the heart muscle) [Siegel 1997]. The FF had a history of hypertension and chronic cardiac ischemia.

Physical Exertion. In addition to medical conditions, sudden cardiac death has been linked to heavy physical exertion [Albert et al. 2000]. Among fire fighters, sudden cardiac events have been associated with alarm response, fire suppression, and heavy exertion during training (including physical fitness training) [Kales et al. 2003; Kales et al. 2007; NIOSH 2007]. The FF's activities at the fire scene would have expended about 7 metabolic equivalents, which is considered moderate physical activity [Gledhill and Jamnik 1992; Ainsworth et al. 2011].

In summary, NIOSH investigators conclude the FF's sudden cardiac death was probably due to an arrhythmia associated with his CHD. The arrhythmia possibly was triggered by responding to the fire scene or the physical exertion associated with his fireground activities. Although the heat index was $88^{\circ} \mathrm{F}$, the FF was on-scene for 10 minutes performing moderate work activity prior to his incident. Therefore, NIOSH investigators do not believe that heat exposure was a factor in his death.

\section{Occupational Medical Standards for}

Structural Fire Fighters. To reduce the risk of sudden cardiac arrest or other incapacitating medical conditions among fire fighters, the NFPA developed NFPA 1582, Standard on Comprehensive Occupational Medical Program for Fire Departments [NFPA 2013a]. This voluntary industry standard provides the components of a preplacement and annual medical evaluation and medical fitness for duty criteria. The FF's CHD was known since 1992, and according to NFPA 1582 this should have restricted his participation in fire suppression tasks. Given that the FF had persistent angina and elevated cholesterol levels, even if an imaging stress test had been performed, NFPA 1582 would have recommended restricting him from fire suppression duties [NFPA 2013a]. This guidance from NFPA is similar to that of the AHA/ACC and the U.S. Department of Transportation for commercial truck drivers [Gibbons 2002; Blumenthal et al. 2007; NFPA 2013a].

\section{Recommendations}

The first three recommendations may have prevented the FF's death. The remaining recommendations address general safety and health issues.

Recommendation \#1: Provide preplacement and annual medical evaluations to all fire fighters in accordance with NFPA 1582, Standard on Comprehensive Occupational Medical Program for Fire Departments, to identify fire fighters at increased risk for CHD.

Guidance regarding the content and frequency of these medical evaluations can be found in NFPA 1582 and in the International Association of Fire Fighters (IAFF)/International Association of Fire Chiefs (IAFC) Fire Service Joint Labor Management Wellness/Fitness Initiative [IAFF, IAFC 2008; NFPA 2013a]. These evaluations are performed to determine fire fighters' medical 


\section{Fire Fighter Suffers Sudden Cardiac Death at Structure Fire - West Virginia}

\section{Recommendations (cont.)}

ability to perform duties without presenting a significant risk to the safety and health of themselves or others. To ensure improved health and safety of candidates and members, and to ensure continuity of medical evaluations, it is recommended the FD comply with this recommendation. However, the fire department is not legally required to follow the NFPA standard or the Wellness/Fitness Initiative.

Applying this recommendation involves economic repercussions and may be particularly difficult for smaller fire departments to implement. To overcome the financial obstacle of medical evaluations, the fire department could urge current members to get annual medical clearances from their private physicians. Another option is having the annual medical evaluations completed by paramedics and emergency medical technicians from the local ambulance service (vital signs, height, weight, visual acuity, and EKG).

This information could then be provided to a community physician, perhaps volunteering his or her time, who could review the data and provide medical clearance or further evaluation, if needed. The more extensive portions of the medical evaluations could be performed by a private physician at the fire fighter's expense, by personal insurance, by a physician volunteer, or paid for by the fire department, city, or state. Sharing the financial responsibility for these evaluations between fire fighters, the fire department, the city, the state, and physician volunteers may reduce the negative financial impact on recruiting and retaining needed fire fighters.

Recommendation \#2: Ensure exercise stress tests are performed on fire fighters at increased risk for $\mathrm{CHD}$.
NFPA 1582, the IAFF/IAFC Fire Service Joint Labor Management Wellness/Fitness Initiative, and the ACC/AHA recommend an exercise stress test for male fire fighters older than 45 with one or more CHD risk factors [Gibbons et al. 2002; IAFF, IAFC 2008; NFPA 2013a]. The FF was over the age of 45 and had known CHD and persistent CHD risk factors. A symptom-limiting exercise stress test may have identified his more recent condition, possibly leading to further evaluation and treatment.

\section{Recommendation \#3: Ensure that fire} fighters are cleared for duty by a physician knowledgeable about the physical demands of fire fighting, the personal protective equipment used by fire fighters, and the various components of NFPA 1582.

Guidance regarding medical evaluations and examinations for structural fire fighters can be found in NFPA 1582 and in the IAFF/IAFC Fire Service Joint Labor Management Wellness/Fitness Initiative [IAFF, IAFC 2008; NFPA 2013a]. According to these guidelines, the fire department should have an officially designated physician who is responsible for guiding, directing, and advising the members with regard to their health, fitness, and suitability for duty. The physician should review job descriptions and essential job tasks required for all fire department positions and ranks to understand the physiological and psychological demands of fire fighters and the environmental conditions under which they must perform, as well as the personal protective equipment they must wear during various types of emergency operations. It is unknown if this FF's personal physician was aware of NFPA 1582. 


\section{Fire Fighter Suffers Sudden Cardiac Death at Structure Fire - West Virginia}

\section{Recommendations (cont.)}

Recommendation \#4: Phase in a mandatory comprehensive wellness and fitness program for fire fighters.

Guidance for fire department wellness/fitness programs to reduce risk factors for cardiovascular disease and improve cardiovascular capacity is found in NFPA 1583, Standard on Health-Related Fitness Programs for Fire Fighters, the IAFF/ IAFC Fire Service Joint Labor Management Wellness/Fitness Initiative, the National Volunteer Fire Council Health and Wellness Guide, and in Firefighter Fitness: A Health and Wellness Guide [IAFF, IAFC 2008; NFPA 2008; USFA 2009; Schneider 2010]. Worksite health promotion programs have been shown to be cost effective by increasing productivity, reducing absenteeism, and reducing the number of work-related injuries and lost work days [Pelletier 2009; Baicker et al. 2010]. Fire service health promotion programs have been shown to reduce coronary artery disease risk factors and improve fitness levels, with mandatory programs showing the most benefit [Dempsey et al. 2002; Womack et al. 2005; Blevins et al. 2006; Poston et al. 2013]. A study conducted by the Oregon Health and Science University reported a savings of more than $\$ 1$ million for each of four large fire departments implementing the IAFF/IAFC wellness/fitness program compared to four large fire departments not implementing a program. These savings were primarily due to a reduction of occupational injury/illness claims with additional savings expected from reduced future nonoccupational healthcare costs [Kuehl et al. 2013].

The fire department does not offer a wellness/ fitness program and exercise equipment is not available in the fire station. Given the fire department's structure, the National Volunteer Fire Council program would be applicable [USFA 2009], but NIOSH would recommend a formal, mandatory wellness/fitness program to ensure all members receive the benefits of a health promotion program.

\section{Recommendation \#5: Perform a candidate} and an annual physical performance (physical ability) evaluation.

NFPA 1500, Standard on Fire Department Occupational Safety and Health Program, requires the fire department to develop physical performance requirements for candidates and members who engage in emergency operations [NFPA 2013b]. Members who engage in emergency operations must be annually qualified (physical ability test) as meeting these physical performance standards for structural fire fighters [NFPA 2013b]. This could be incorporated into the annual task-level training program.

\section{Recommendation \#6: Provide fire fighters with medical clearance to wear $S C B A$ as part of the fire department's medical evaluation program.}

The Occupational Safety and Health Administration (OSHA) revised respiratory protection standard requires employers to provide medical evaluations and clearance for employees using respiratory protection [29 CFR 1910.134]. These clearance evaluations are required for private industry employees and public employees in states operating OSHA-approved state plans. West Virginia does not operate an OSHAapproved state plan; therefore, the fire department is not required to ensure all members have been medically cleared to wear an SCBA. However, 


\section{Fire Fighter Suffers Sudden Cardiac Death at Structure Fire - West Virginia}

\section{Recommendations (cont.)}

NIOSH investigators recommend voluntary compliance with this recommendation to improve fire fighter health and safety.

\section{Recommendation \#7: Conduct annual respirator fit testing.}

The OSHA respiratory protection standard requires employers whose employees are required to use a respirator (e.g., an SCBA) to have a formal respiratory protection program, including annual fit testing [29 CFR 1910.134]. Therefore, each member should have his or her own SCBA facepiece, or the fire department would have to ensure enough facepieces of each size were made available on each fire apparatus. As mentioned previously, West Virginia does not operate an OSHA-approved state plan; therefore, the fire department is not required to follow OSHA standards [OSHA 2014]. Nevertheless, NIOSH investigators recommend voluntary compliance with this standard to ensure proper fitting personal protective equipment to improve safety and health.

\section{References}

AHA [2012]. Understand your risk for arrhythmia. Dallas, TX: American Heart Association. [http://www.heart.org/HEARTORG/Conditions/ Arrhythmia/UnderstandYourRiskforArrhythmia/Understand-Your-Risk-for-Arrhythmia UCM 002024_Article.jsp]. Date accessed: May 2014.
AHA [2014]. Understand your risk of heart attack. Dallas, TX: American Heart Association. [http:// www.heart.org/HEARTORG/Conditions/HeartAttack/UnderstandYourRiskofHeartAttack/Understand-Your-Risk-of-Heart-Attack UCM 002040 Article.jsp]. Date accessed: May 2014.

Ainsworth BE, Haskell WL, Herrmann SD, Meckes N, Bassett DR Jr, Tudor-Locke C, Greer JL, Vezina J, Whitt-Glover MC, Leon AS [2011]. Compendium of physical activities: a second update of codes and MET values. Med Sci Sports Exerc 43(8):1575-1581.

Albert CM, Mittleman MA, Chae CU, Lee IM, Hennekens CH, Manson JE [2000]. Triggering of sudden death from cardiac causes by vigorous exertion. N Engl J Med 343(19):1355-1361.

Baicker K, Cutler D, Song Z [2010]. Workplace wellness programs can generate savings. Health Affairs 29(2):1-8.

Blevins JS, Bounds R, Armstrong E, Coast JR [2006]. Health and fitness programming for fire fighters: does it produce results? Med Sci Sports Exerc 38(5):S454.

Blumenthal RS, Epstein AE, Kerber RE [2007]. Expert panel recommendations. Cardiovascular disease and commercial motor vehicle driver safety. [http://www.mrb.fmcsa.dot.gov/documents/CVD Commentary.pdf]. Date accessed: May 2014.

CDC (Centers for Disease Control and Prevention) [2011]. BMI - Body Mass Index. [http:// www.cdc.gov/healthyweight/assessing/bmi/index]. Date accessed: May 2014. 


\section{Fire Fighter Suffers Sudden Cardiac Death at Structure Fire - West Virginia}

\section{References (cont.)}

CFR. Code of Federal Regulations. Washington, DC: U.S. Government Printing Office, Office of the Federal Register.

Davies MJ [1992]. Anatomic features in victims of sudden coronary death. Coronary artery pathology. Circulation 85[Suppl I]:I-19-24.

Dempsey WL, Stevens SR, Snell CR [2002]. Changes in physical performance and medical measures following a mandatory firefighter wellness program. Med Sci Sports Exerc 34(5):S258.

Farb A, Tang AL, Burke AP, Sessums L, Liang Y, Virmani R [1995]. Sudden coronary death: frequency of active lesions, inactive coronary lesions, and myocardial infarction. Circulation 92(7):1701-1709.

Gibbons RJ, Balady GJ, Bricker JT, Chaitman BR, Fletcher GF, Froelicher VF, Mark DB, McCallister BD, Mooss AN, O’Reilly MG, Winters WL Jr., Antman EM, Alpert JS, Faxon DP, Fuster V, Gregoratos G, Hiratzka LF, Jacobs AK, Russell RO, Smith SC Jr. [2002]. ACC/AHA 2002 guideline update for exercise testing: a report of the American College of Cardiology/American Heart Association Task Force on Practice Guidelines. Circulation 106(14):1883-1892.

Gledhill N, Jamnik VK [1992]. Characterization of the physical demands of firefighting. Can J Sport Sci 17(3):207-213.
Greenland P, Alpert JS, Beller GA, Benjamin EJ, Budoff MJ, Fayad ZA, Foster E, Hlatky MA, Hodgson JM, Kushner FG, Lauer MS, Shaw LJ, Smith SC Jr., Taylor AJ, Weintraub WS, Wenger NK [2010]. 2010 ACCF/AHA guideline for assessment of cardiovascular risk in asymptomatic adults: a report of the American College of Cardiology Foundation/American Heart Association Task Force on Practice Guidelines. Circulation 122(25):e584-e636.

IAFF, IAFC [2008]. The fire service joint labor management wellness/fitness initiative. 3rd ed. Washington, DC: International Association of Fire Fighters, International Association of Fire Chiefs.

Kales SN, Soteriades ES, Christoudias SG, Christiani DC [2003]. Firefighters and on-duty deaths from coronary heart disease: a case control study. Environ Health: a global access science source. 2:14. [http://www.ehjournal.net/content/2/1/14]. Date accessed: May 2014.

Kales SN, Soteriades ES, Christophi CA, Christiani DC [2007]. Emergency duties and deaths from heart disease among fire fighters in the United States. N Engl J Med 356(12):1207-1215.

Kuehl KS, Elliot DL, Goldberg L, Moe EL, Perrier E, Smith J [2013]. Economic benefit of the PHLAME wellness programme on firefighter injury. Occ Med 63(3):203-209.

Levy D, Garrison RJ, Savage DD, Kannel WB, Castelli WP [1990]. Prognostic implications of echocardiographically determined left ventricular mass in the Framingham Heart Study. N Engl J Med 323(24):1706-1707. 


\section{Fire Fighter Suffers Sudden Cardiac Death at Structure Fire - West Virginia}

\section{References (cont.)}

Libby P [2013]. Mechanisms of acute coronary syndromes and their implications for therapy. $\mathrm{N}$ Engl J Med 368(21):2004-2013.

Mayo Clinic [2013]. Heart arrhythmias. [http:// www.mayoclinic.com/health/heart-arrhythmias/ DS00290/METHOD=print\&DSECTION=all].

Date accessed: May 2014.

Meyerburg RJ, Castellanos A [2008]. Cardiovascular collapse, cardiac arrest, and sudden cardiac death. In: Fauci AS, Braunwald E, Kasper DL, Hauser SL, Longo DL, Jameson JL, Loscalzo J, eds. Harrison's principles of internal medicine. 17th ed. New York: McGraw-Hill, pp. 1707-1713.

NFPA [2008]. Standard on health-related fitness programs for fire fighters. Quincy, MA: National Fire Protection Association. NFPA 1583.

NFPA [2013a]. Standard on comprehensive occupational medical program for fire departments. Quincy, MA: National Fire Protection Association. NFPA 1582.

NFPA [2013b]. Standard on fire department occupational safety and health program. Quincy, MA: National Fire Protection Association. NFPA 1500.

NHLBI [2012]. Who is at risk for coronary artery disease? National Heart, Lung, and Blood Institute. [http://www.nhlbi.nih.gov/health/health-topics/topics/cad/atrisk.html]. Date accessed: May 2014.
NIOSH [2007]. NIOSH alert: preventing fire fighter fatalities due to heart attacks and other sudden cardiovascular events. Cincinnati, OH: U.S. Department of Health and Human Services, Centers for Disease Control and Prevention, National Institute for Occupational Safety and Health, DHHS (NIOSH) Publication No. 2007-133. [http://www. cdc.gov/niosh/docs/2007-133/]. Date accessed: May 2014.

NOAA [2013]. Quality controlled local climatological data: (final). Hourly observations table, Yeager Airport June 24, 2013. [http://cdo.ncdc.noaa.gov/ qclcd/QCLCD]. Date accessed: May 2014.

OSHA (Occupational Safety and Health Administration) [2014]. State occupational safety and health plans. [http://www.osha.gov/dcsp/osp/index.html]. Date accessed: May 2014.

Pelletier KR [2009]. A review and analysis of the clinical and cost-effectiveness studies of comprehensive health promotion and disease management programs at the worksite: update VII 2004-2008. J Occup Environ Med 51(7):822-837.

Poston WSC, Haddock CK, Jahnke SA, Jitnarin N, Day RS [2013]. An examination of the benefits of health promotion programs for the national fire service. BMC Pub Health 13(1):805-819.

Schneider EL [2010]. Firefighter fitness: a health and wellness guide. New York: Nova Science Publishers.

Siegel RJ [1997]. Myocardial hypertrophy. In: Bloom S, ed. Diagnostic criteria for cardiovascular pathology acquired diseases. Philadelphia, PA: Lippencott-Raven, pp. 55-57. 


\section{Fire Fighter Suffers Sudden Cardiac Death at Structure Fire - West Virginia}

\section{References (cont.)}

USFA [2009]. Health and wellness guide for the volunteer fire and emergency services. Emmitsburg, MD: Federal Emergency Management Agency; United States Fire Administration. Publication No. FA-321.

Womack JW, Humbarger CD, Green JS, Crouse SF [2005]. Coronary artery disease risk factors in firefighters: effectiveness of a one-year voluntary health and wellness program. Med Sci Sports Exerc 37(5):S385.

\section{Investigator Information}

This incident was investigated by the NIOSH Fire Fighter Fatality Investigation and Prevention Program, Cardiovascular Disease Component in Cincinnati, Ohio. Mr. Tommy Baldwin (MS) led the investigation and co-authored the report. Mr. Baldwin is a Safety and Occupational Health Specialist, a National Association of Fire Investigators (NAFI) Certified Fire and Explosion Investigator, an International Fire Service Accreditation Congress (IFSAC) Certified Fire Officer I, and a former Fire Chief and Emergency Medical Technician. Dr. Thomas Hales (MD, MPH) provided medical consultation and co-authored the report. Dr. Hales is a member of the NFPA Technical Committee on Occupational Safety and Health, and Vice-Chair of the Public Safety Medicine Section of the American College of Occupational and Environmental Medicine (ACOEM). 


\section{Fire Fighter Suffers Sudden Cardiac Death at Structure Fire - West Virginia}

\section{Appendix A}

\section{Autopsy Findings}

- Coronary heart disease

- Coronary artery atherosclerosis

- Severe (near total) focal narrowing of the left anterior descending coronary artery

- Severe (near total) focal narrowing of the right coronary artery

- Severe (80\%) focal narrowing of the left circumflex coronary artery

- Microscopic: focally transmural myocardial scarring of the posterior left ventricular wall, consistent with a remote (old) heart attack

- No evidence of recent coronary artery thrombus (blood clot)

- Cardiomegaly (enlarged heart): heart weighed 750 grams (g) (predicted normal weight is $377 \mathrm{~g}$ (ranges between $285 \mathrm{~g}$ and $497 \mathrm{~g}$ as a function of sex, age, and body weight) [Silver and Silver 2001]

○ Concentric left ventricular hypertrophy and left ventricular dilatation

$\circ$ Left ventricle thickened $(2.0$ centimeter $[\mathrm{cm}])$

- Normal at autopsy is $0.76-0.88 \mathrm{~cm}$ [Colucci and Braunwald 1997]

- Normal by echocardiographic measurement is 0.6-1.0 cm [Connolly and Oh 2012]

- Pericardial fibrous adhesions associated with the FF's bypass surgery

- Normal cardiac valves

- No evidence of a pulmonary embolus (blood clot in the lung arteries)

- Blood tests for drugs and alcohol were negative including a normal carboxyhemoglobin level suggesting no exposure to fire smoke containing carbon monoxide.

\section{References}

Colucci WS, Braunwald E [1997]. Pathophysiology of heart failure. In: Braunwald, ed. Heart disease. 5th ed. Philadelphia, PA: W.B. Saunders Company, p. 401.

Connolly HM, Oh JK [2012]. Echocardiography. In: Bonow RO, Mann DL, Zipes DP, Libby P, Braunwald E, eds. Heart disease: a text of cardiovascular medicine. 9th ed. Vol. 1. Philadelphia, PA: Elsevier Saunders, p. 216.

Silver MM, Silver MD [2001]. Examination of the heart and of cardiovascular specimens in surgical pathology. In: Silver MD, Gotlieb AI, Schoen FJ, eds. Cardiovascular pathology. 3rd ed. Philadelphia, PA: Churchill Livingstone, pp. 8-9. 